\title{
Subtypes, Risk Factors and Site of Stenosis of Ischaemic Stroke in a University Hospital in Bangladesh
}

\author{
Mohammad Shahidullah" ${ }^{1 *}$, Nahid Sultana², Subash Kanti Dey ${ }^{1}$, Anis Ahmed ${ }^{1}$
}

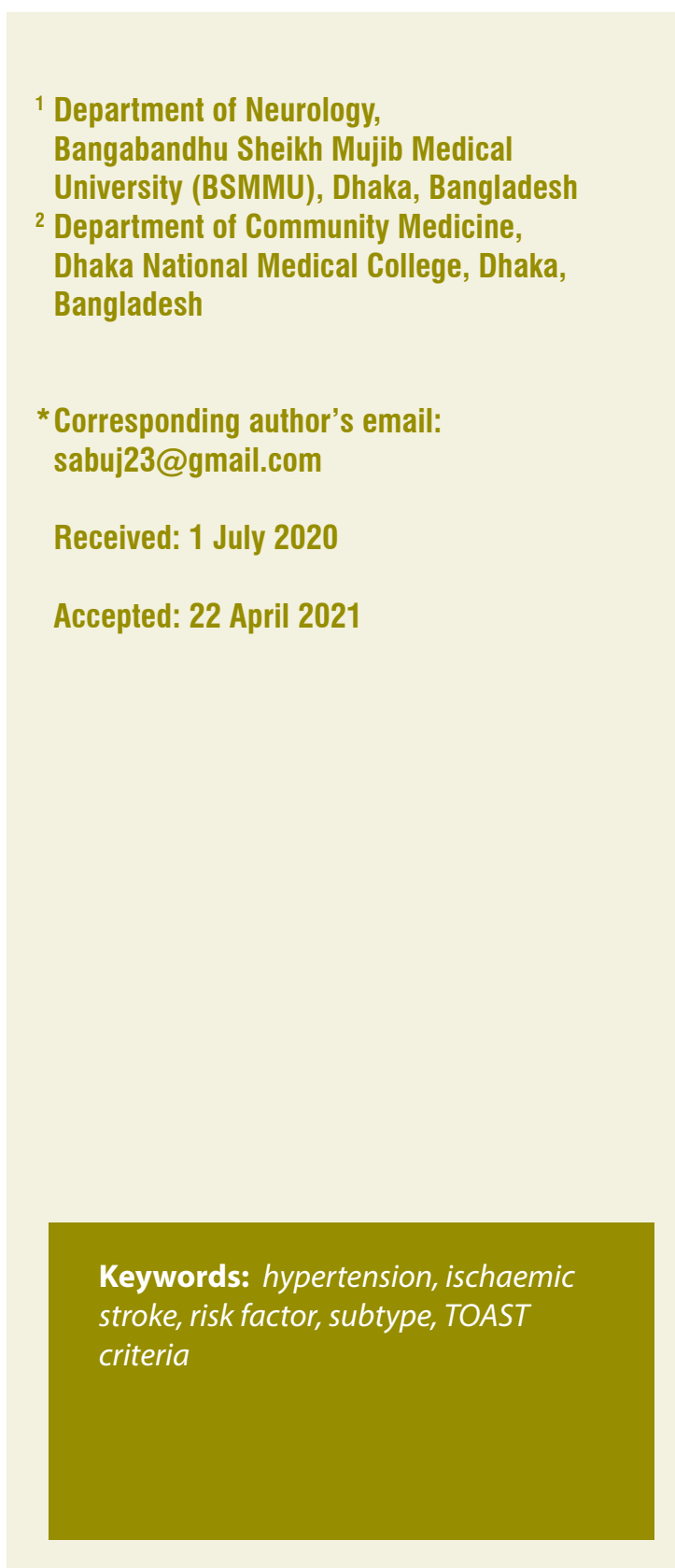

\section{ABSTRACT}

Stoke is the second most common cause of death and the most common cause of adult disability. To plan an efficient evaluation and treatment of an individual patient with ischaemic stroke, the clinician should be familiar with the subtyping of ischaemic stroke patients and the risk factors analysis of different aetiology. Eight hundred seventy-seven (877) patients have been selected for this cross-sectional study conducted in a university hospital of Bangladesh from 2014 to 2018, to whom brain imaging [Computed Tomography (CT)/ Magnetic Resonance Imaging (MRI)], vascular imaging [Magnetic Resonance Angiogram (MRA), Digital Subtraction Angiogram (DSA)], ECG and echocardiography have been done. We did subtyping according to TOAST criteria. The mean age of patients was $60.5 \pm 11$ years. Most patients (29.33\%) belonged to the age group $51-60$, where $70.47 \%$ of subjects were male and $29.53 \%$ were female. In this study, $\mathbf{4 3 . 8 7 \%}$ of patients were in the large artery atherosclerosis group, $23.83 . \%$ in the small vessel occlusion group, $8.46 \%$ in the cardiac embolism group, $19.30 \%$ in the undetermined aetiology group and $4.54 \%$ in other determined aetiology. Among risk factors hypertension, diabetes mellitus, dyslipidaemia

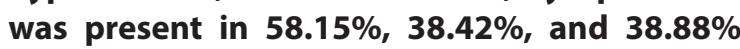
of patients, respectively. In ischaemic stroke patients, large artery atherosclerosis was the most common subtype and hypertension was significant in this group. Extracranial stenosis was more common in ischaemic stroke. 


\section{INTRODUCTION}

Worldwide stroke is the second most common cause of death (Katan \& Luft, 2018) and the most known cause of severe disability (Adamson et al., 2004). Worldwide 5.7 million people died in 2005 and projected to rise to 7.8 million in the year 2030. According to Global burden of disease (GBD) 2016, death due to stroke in South Asia has increased from $15 \%$ to $21 \%$ and the mean global lifetime risk of stroke has increased from $22.8 \%$ to $24.9 \%$. Strokes can be classified into ischaemic and haemorrhagic types (Donkor, 2018). Worldwide about 69\% of stroke, $71 \%$ of stroke-related death and $78 \%$ of DALYs (disability-adjusted life years) lost occurred in low-income and middleincome countries. Over the last forty years, the stroke incidence in low- and middle-income countries has become more than doubled. During this time, stroke incidence has declined by $42 \%$ in high-income countries. Globally there was a $25 \%$ increase in the incidence of people ranging from $20-64$ years of age, a $23 \%$ increase in prevalence in high-income countries, increase in mortality rate in South Asia from 1990 to 2010 (Feigin et al., 2010).

Stroke is the third leading cause of death in Bangladesh after heart disease and infectious disease. The mortality rate of stroke was $6 \%$ in 2006 and $8.57 \%$ in 2011. The prevalence rate of stroke in Bangladesh is around $0.3 \%$ until the year 2010 (Islam et al., 2013).

Ischaemic stroke is a heterogeneous disorder and there are multiple mechanisms for it (Ay et al., 2007). Pathophysiologically ischaemic stroke may occur due to thrombosis of large or small vessels, emboli from the heart or artery, hypoperfusion in the watershed area or border zone (Deb et al.,2010). In the western population, cardioembolic stroke is the dominant cause; in India, large artery atherosclerosis and Pakistan, lacunar stroke is the most common cause of ischaemic stroke (Assad et al., 2018). The important risk factors are uncontrolled hypertension, dyslipidaemia, diabetes mellitus, coronary artery disease, atrial fibrillation, smoking and those vary with stroke subtypes (Beg et al., 2015). Various aetiologies often result in variation in outcome, treatment, and likelihood of recurrence in ischaemic stroke. Large infarct resulting from occlusion of the internal carotid artery or proximal middle cerebral artery has the worst prognosis. Mortality is higher among patients with large-artery atherosclerotic lesions than lacunar stroke. Recurrent strokes are more common in patients with cardioembolic stroke. Anticoagulants may be prescribed to prevent recurrent cardio-embolic stroke. Carotid stenting and carotid endarterectomy are useful in preventing recurrent stroke with large artery atherosclerosis. Thus, determining the cause of stroke does influence the outcome and choice of treatment.

It is difficult to include all stroke subtypes within a single classification system. The TOAST classification of subtypes was introduced to produce uniformity. The TOAST classification was the first classification system based on stroke mechanisms, vascular risk factors, early and long-term recurrence and survival were found to be different among the ischaemic stroke subtypes classified by TOAST. The Trial of Org 10172 in Acute Stroke Treatment (TOAST) classification was introduced in 1993. It is divided into 5 groups: Large Artery Atherosclerosis (LAA), Cardioembolism (CE), Small Vessel Occlusion (SVO), Stroke of Other Determined Etiology (SODE), Stroke of Undetermined Etiology (SUDE) (Adams et al., 1993). In a retrospective study, TOAST classification had been proven as valid and reliable (Fure et al., 2005).

Several studies had been done to identify the risk factors in each subtype in a different community. Data is scarce regarding ischaemic stroke subtypes and their risk factors in Bangladeshi people. We wanted to know the common aetiology, subtypes, and risk factors of each subtype in ischaemic stroke. 


\section{MATERIALS AND METHODS}

This was a cross-sectional study conducted in Bangabandhu Sheikh Mujib Medical University (BSMMU), Dhaka which is a tertiary care hospital and postgraduate institute. Here patients get admitted through outdoor patient department service and no emergency admission was available. In this institute, interventional neurology works that include cerebral DSA, carotid stenting, vertebral stenting, endovascular coiling, and embolization are done by a neurologist.

This study was done in the Neurology Department of BSMMU from March 2014 to November 2018. After the approval from Institutional Review Board (NO. BSMMU/2014/3938), informed written consent was taken from all patients. Stroke was defined according to WHO criteria as features of focal and global cerebral dysfunction that lasts for more than 24 hours with no other than vascular cause. Any ischaemic stroke patients of more than 18 years of age and within 10 days of symptom onset, willing to be included were enrolled in this study. Any TIA, venous stroke or haemorrhagic stroke patients were excluded from enrollment.

A purposive non-random sampling method had been used in this study. The patients were diagnosed with ischaemic stroke by history, clinical examinations, and brain imaging. A total of 1,978 ischaemic stroke patients were enrolled in this study. Among them, 877 patients had been selected for subtyping of ischaemic stroke, to whom vascular imaging (MRA, CTA, DSA), ECG, echocardiography and other relevant biochemical tests had been done. All patients could not do the necessary investigations for subtyping due to financial constraints.
Demographic data and information about risk factors (hypertension, diabetes, dyslipidaemia, history of the previous stroke, and cardiac disease) were documented.

Subtyping of the ischaemic stroke into 5 categories was done according to the TOAST criteria (Adams et al., 1993). It is a commonly used classification system that uses the clinical feature, brain imaging findings, and vascular imaging along with some ancillary test.

1. Large Artery Atherosclerosis (LAA) diagnosed by clinical features of cortical dysfunction and criteria of vascular imaging that is $>50 \%$ stenosis or occlusion of the major artery or cortical artery.

2. Cardio-embolism (CE) diagnosed by major risk factors for embolism at least one and no apparent evidence of other subtypes.

3. Small Vessel Occlusion (SVO) diagnosed by clinical features of lacunar syndrome with no cortical features and lesion in brain imaging should be $<1.5 \mathrm{~cm}$.

4. Stroke of Other Determined Etiology (SODE) diagnosed by other evidence of stroke risk factors as hypercoagulability, evidence of vasculitis, dissection, and Moyamoya found in vascular imaging.

5. Stroke of Undetermined Etiology (SUDE) diagnosed by when two or more causes were identified. Subtyping was done after all documents were available to the patient.

Statistical analysis was performed using software SPSS 20 for windows. Numerical data are presented as mean \pm standard deviation (SD) and risk factors and subtyping are presented as percentages.

\section{RESULTS}

Of all 877 patients, 606 (69.10\%) were male and $271(30.90 \%)$ were female (Table 1). 
Table 1 Distribution of gender among the subtypes $(n=877)$

\begin{tabular}{|l|c|c|c|}
\hline Subtype & Male & Female & Total \\
\hline Large Artery Atherosclerosis (LAA) & 273 & 112 & 785 \\
\hline Cardio-embolism (CE) & 22 & 52 & 209 \\
\hline Small Vessel Occlusion (SVO) & 153 & 56 & 40 \\
\hline Stroke of Other determined Etiology (SODE) & 24 & 16 & 169 \\
\hline Stroke of Undetermined Etiology (SUDE) & 134 & 35 & $877(100 \%)$ \\
\hline Total & $606(69.10 \%)$ & $271(30.90 \%)$ & 74 \\
\hline
\end{tabular}

The mean age of patients was $60.5 \pm 11$ years. Most patients (32.27\%) belonged to the age group $51-60$ years, followed by $26.11 \%$ from $61-70$ years age groups. A total of $67.5 \%$ was above the age of 50 years (Table 2).

Table 2 Distribution of age among the subtypes $(n=877)$

\begin{tabular}{|l|c|c|c|c|c|c|c|}
\hline Subtype & $\begin{array}{c}<\mathbf{3 0} \\
\text { yrs }\end{array}$ & $\begin{array}{c}\mathbf{3 1 - 4 0} \\
\mathbf{y r s}\end{array}$ & $\begin{array}{c}\mathbf{4 1 - 5 0} \\
\mathbf{y r s}\end{array}$ & $\begin{array}{c}\mathbf{5 1 - 6 0} \\
\text { yrs }\end{array}$ & $\begin{array}{c}\mathbf{6 1 - 7 0} \\
\text { yrs }\end{array}$ & $\begin{array}{c}>\mathbf{7 0} \\
\text { yrs }\end{array}$ & Total \\
\hline Large Artery Atherosclerosis (LAA) & 4 & 9 & 64 & 165 & 106 & 37 & 385 \\
\hline Cardio-embolism (CE) & 11 & 11 & 34 & 7 & 6 & 5 & 74 \\
\hline Small Vessel Occlusion (SVO) & 0 & 10 & 66 & 57 & 60 & 16 & 209 \\
\hline Stroke of Other determined Etiology (SODE) & 10 & 17 & 3 & 7 & 3 & 0 & 40 \\
\hline Stroke of Undetermined Etiology (SUDE) & 7 & 14 & 25 & 47 & 54 & 22 & 169 \\
\hline Total & 32 & 61 & 192 & 283 & 229 & 80 & 877 \\
\hline Percentage & 3.65 & 6.95 & 21.90 & 32.27 & 26.11 & 9.12 & 100 \\
\hline
\end{tabular}

The most common stroke subtypes were Large Artery Atherosclerosis LAA (43.87\%), followed by Small Vessel Occlusion SVO (23.83\%), Stroke of Undetermined Etiology SUDE (19.30\%), Cardioembolism CE (8.46\%), and Stroke of Other Determined Etiology SODE (4.54\%) (Table 3).

Table 3 Distribution of the subtypes of ischaemic stroke among the participants ( $n=877$ )

\begin{tabular}{lcc}
\hline Subtype & Number of patients & Percentage \\
\hline Large Artery Atherosclerosis (LAA) & 385 & 43.87 \\
Cardio-embolism (CE) & 74 & 8.46 \\
Small Vessel Occlusion (SVO) & 209 & 23.83 \\
Stroke of Other Determined Etiology (SODE) & 40 & 4.54 \\
Stroke of Undetermined Etiology (SUDE) & 169 & 19.30 \\
\hline Total & 877 & 100 \\
\hline
\end{tabular}

Regarding risk factors, hypertension was found in $58.15 \%$ of patients followed by dyslipidaemia and diabetes mellitus at $38.88 \%$ and $38.42 \%$ respectively. Among the risk factors, hypertension was significantly high $(82.59 \%$ of 385 ) in the large artery atherosclerosis group which was statistically significant. Diabetes mellitus was also high in the large artery atherosclerosis group (46.23\% of 385), followed by small vessel occlusion (43.06\% of 209) (Table 4). 
Table 4 Distribution of risk factors of different etiology $(n=877)$

\begin{tabular}{lllll}
\hline Category & Previous H/O stroke & DM & HTN & DL \\
\hline Large Artery Atherosclerosis (LAA) & $53(13.77 \%)$ & $178(46.23 \%)$ & $318(82.59 \%)$ & $189(49.09 \%)$ \\
Cardio-embolism (CE) & $6(8.1 \%$ & $3(4.05 \%)$ & $10(13.51 \%)$ & $9(12.16 \%)$ \\
Small Vessel Occlusion (SVO) & $12(5.74 \%)$ & $90(43.06 \%)$ & $87(41.62 \%)$ & $77(36.84 \%)$ \\
Stroke of Other Determined Etiology (SODE) & $3(7.5 \%)$ & $5(12.5 \%)$ & $4(10 \%)$ & $7(17.5 \%)$ \\
Stroke of Undetermined Etiology (SUDE) & $17(10.09 \%)$ & $61(36.09 \%)$ & $91(53.84 \%)$ & $59(34.92 \%)$ \\
\hline Total & $94(10.37 \%)$ & $337(38.42 \%)$ & $510(58.15 \%)$ & $341(38.88 \%)$ \\
\hline $\boldsymbol{p}$-value & 0.962 & 0.201 & $0.005^{*}$ & 0.201 \\
\hline
\end{tabular}

HTN: Hypertension, DM: Diabetes Mellitus, DL: Dyslipidaemia

Among the large artery atherosclerosis group, 189 patients (49.09\%) had $70-99 \%$ stenosis followed by 116 (30.12\%) patients who had complete occlusion (Table 5). Also, 75.56\% of stenosis was extracranial and $24.44 \%$ was intracranial (Figure 1).

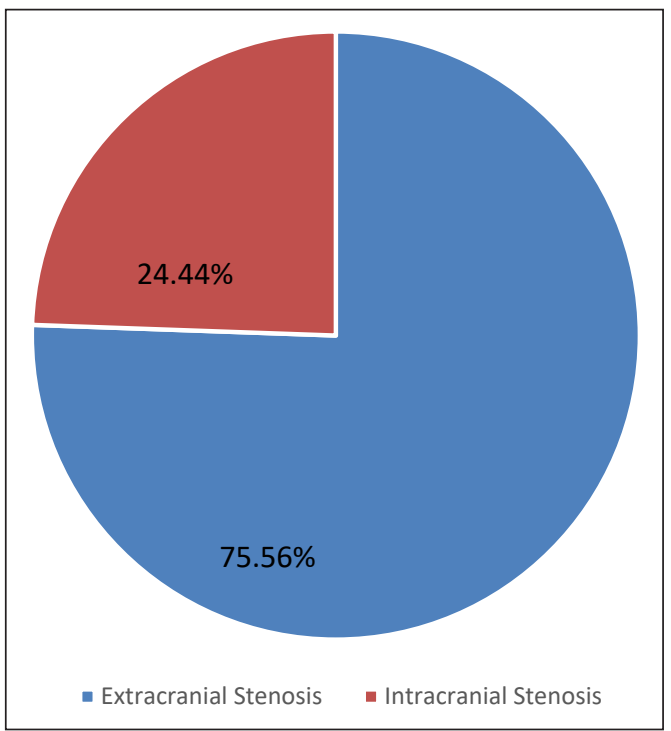

Figure 1 Distribution of site of significant (>50\% stenosis) vascular pathology

Table 5 Degree of stenosis among different aetiology $(n=877)$

\begin{tabular}{|c|c|c|c|}
\hline $\begin{array}{c}\text { Degree } \\
\text { of stenosis }\end{array}$ & $\begin{array}{c}\text { Large Artery } \\
\text { Atherosclerosis (LAA) }\end{array}$ & $\begin{array}{c}\text { Stroke of Other Determined } \\
\text { Etiology (SODE) }\end{array}$ & $\begin{array}{c}\text { Stroke of Undetermined } \\
\text { Etiology (SUDE) }\end{array}$ \\
\hline$<50 \%$ & 0 & $17(42.50 \%)$ & $74(43.79 \%)$ \\
$50-69 \%$ & $80(20.79 \%)$ & $4(10.00 \%)$ & $39(23.07 \%)$ \\
$70-99 \%$ & $189(49.09 \%)$ & $3(7.50 \%)$ & $43(25.45 \%)$ \\
$100 \%$ & $116(30.12 \%)$ & $16(40.00 \%)$ & $13(7.69 \%)$ \\
\hline Total & 385 & 40 & 169 \\
\hline
\end{tabular}




\section{DISCUSSION}

The goal of this study was to analyze and evaluate the subtyping of ischaemic stroke and the risk factor of each subtype according to TOAST criteria. A total of $69.10 \%$ of respondents of this study was male, and it showed male predominance than female in ischaemic stroke and almost two-thirds of patients are above the age of 50. Beg et al. (2015) found in India that the number of males is greater than that of female, Bhowmik et al. (2016) found $67.7 \%$ in Bangladesh, Shakya et al. (2019) found $51.1 \%$ in Nepal. The finding is also similar in developed countries. A study of 1,136 patients done by Caso et al. (2010) found that the number of females was lower (46\%) than that of the male. Bender et al. (2017) found female dominance $(52 \%)$ in their study, but they took both ischaemic and haemorrhagic stroke including SAH in their study.

The mean age of this present study was $60.5 \pm 11$ years which was comparable to the study done by (Beg et al., 2015). A study done by Cotter et al. (2011) found that the mean age was 63.2, and another study of 679 patients done by Bhowmik et al. (2016) found the mean age to be 60.4 years. In Nepal, Shakya et al. (2019) conducted a study where the mean age was 63.2 years. However, in Europe, Caso et al. (2010) found the mean age as 72.68 ( \pm 13.27$)$.

This study revealed that with $43.67 \%(n=$ 385), Large Artery Atherosclerosis (LAA) is the most common subtype. Kaul et al. (2018) found $37.6 \%$ as LAA in India of 2,072 total patients like our findings. Again, a study conducted in Singapore by De Silva et al. (2007) within the South Asian population found $41 \%$ as LAA. Harris et al. (2018) in Indonesia found 59.6\%, as LAA. Also, in the Chinese population, the result was similar to $37.4 \%$ which was done by Tan et al. (2018). In India, a similar study was done by Kannan et al. (2017). In LAA, imaging finding of infarction should be more than $1.5 \mathrm{~cm}$ in the cortical, subcortical, cerebellar or brain stem region (Figures 2 and 3). Supporting evidence by angiography of stenosis of more than $50 \%$ in extracranial (Figure 4) or intracranial (Figure 5) was evident.

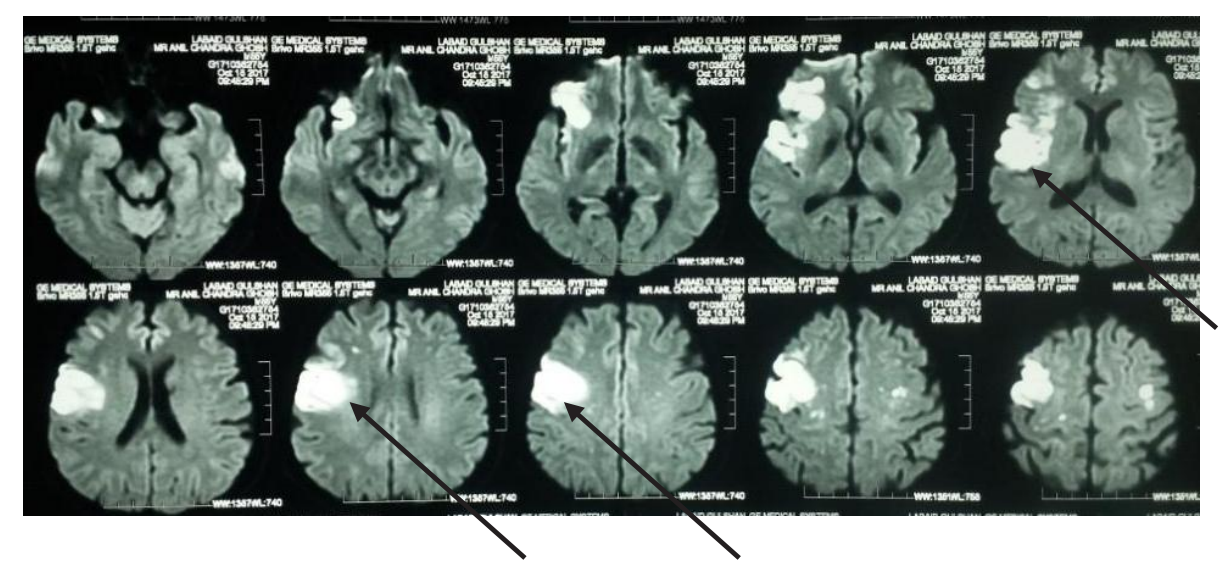

Figure $2 \mathrm{MRI}$ of a patient of LAA (arrow showed infarction in both cortical and subcortical area which was $>1.5 \mathrm{~cm}$ ) 


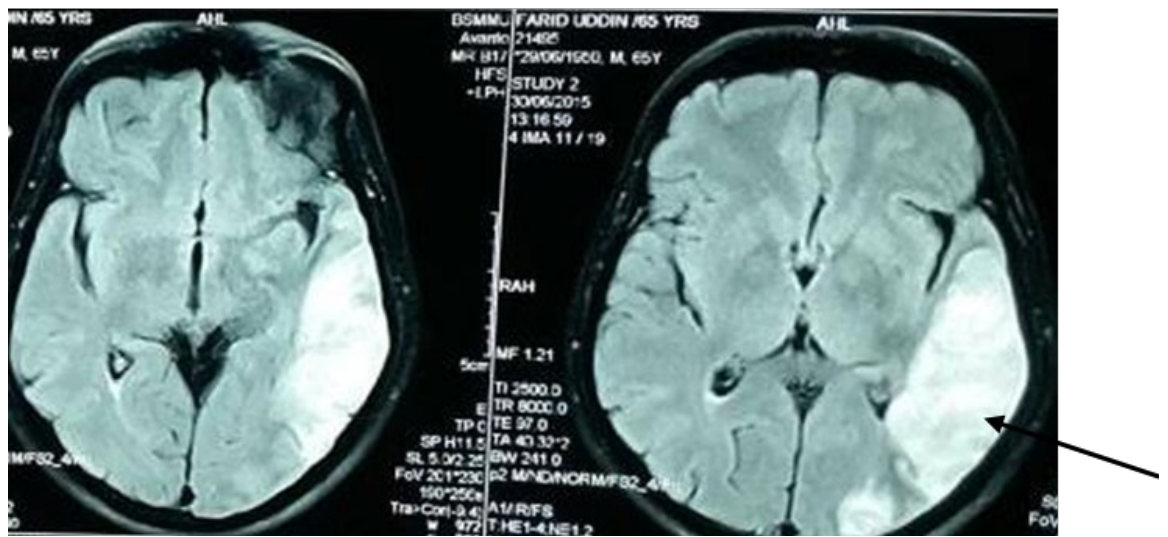

Figure 3 Large infarction in MCA territory (arrow showed infarction in left MCA territory, this is in favour of large artery atherosclerosis)

Contrary, Kang et al. (2003); KolominskyRabas et al. (2001); Tian and Fan (2018) found $15.3 \%, 16.28 \%$, and $31 \%$ of ischaemic stroke patients as LAA respectively. This variation could be due to ethnic origin. The use of cerebral DSA was more in our study because our department has more facility for it and MRA or CTA is more expensive than DSA. This may be a cause for finding more LAA in this study.

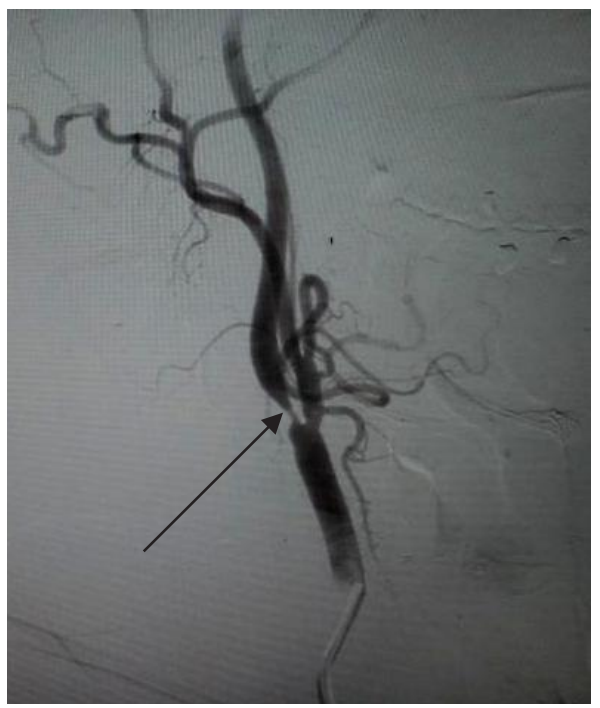

Figure 4 Severe Stenosis of ICA Origin (Arrow showed severe stenosis at the origin of Internal Carotid Artery, itls in favor of large artery atherosclerosis)

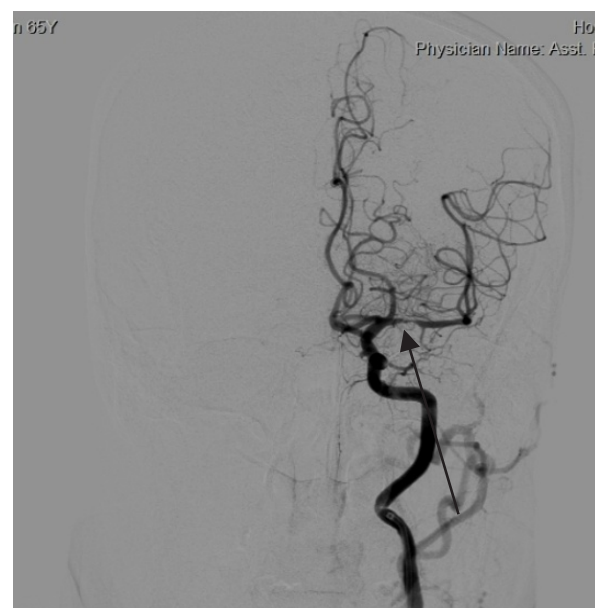

Figure 5 Left MCA severe stenosis (arrow showed severe stenosis of the left middle cerebral artery after the bifurcation of internal carotid artery)

In this research, Small Vessel Occlusion (SVO) was $23.83 \%$ which was the second most common subtype. Most of the studies done in this sub-continent and South Asia found the comparable result to this study. Kaul et al. (2018) and Kannan et al. (2017) in India, Assad et al. (2018) in Pakistan, Harris et al. (2018) in Indonesia found 19.9\%, 17.24\%, and $27.7 \%$ respectively. Kannan et al. (2017) and Kaul et al. (2018) also found a similar result in their study with $23.4 \%$ and $18 \%$ respectively. In developed countries, the percentage of SVO is somewhat higher compared to our study. Jacková (2017) in the Crez Republic, Lee et al. (2010) in Taiwan, De Silva et al. (2007) in Singapore found 45.2\%, $31.4 \%, 39.4 \%$, and $35 \%$ respectively. 
We found $8.46 \%$ of total ischaemic stroke patients as Cardio-embolism (CE) like another study done like Tian et al. (2018) as $8 \%$ and, Kaul et al. (2018) in India as 10\%. In contrast, Kolominsky-Rabas et al. (2001) found CE as 27\%, Kang et al. (2003) as $40.59 \%$. This may be due to different population origin and the increased rate of cardiac disease, more extensive work like ECG, Echocardiography, Holter monitoring, Transesophageal echocardiography, and less cerebral angiography for evaluation of ischaemic stroke patients.

In this study, hypertension was the most common risk factor (58.15\%) followed by dyslipidaemia (38.88\%) and diabetes (38.42\%). This is consistent with the other study in this subcontinent. In Pakistan, Assad et al. (2018), Manosalva and Jeerakathil (2016), Taj et al. (2010) and in India, Pathak et al. (2018) found hypertension $62.7 \%, 71 \%, 78 \%$ and $65 \%$ respectively. This finding is also consistent with a study in the Middle East, Korea as Kim et al. (2003), Rukn et al. (2019) found hypertension as $66 \%$ and $61.1 \%$ respectively. Assad et al. (2018) also found diabetes mellitus as $36.6 \%$ which was also comparable to this study.

In this study, hypertension was significantly present in large artery atherosclerosis which is also comparable with Assad et al. (2018). In our study, 75.56\% of stenosis was extracranial. This finding is also comparable to the findings of Flaherty et al. (2013) and Barnett et al. (2010) which was $78.63 \%$ and $78.4 \%$ respectively.

Some limitations exist in this study as it was a hospital-based study and cardiac evaluation was limited only to ECG and echocardiography.

\section{CONCLUSION}

The most common subtype of ischaemic stroke in this study was the large artery atherosclerosis group and extracranial stenosis was more common than intracranial stenosis. This finding will lead to a future study that can identify the pathophysiology of LAA in this ethnic group. There were differences in risk factors between the subtypes of ischaemic stroke. Hypertension was significantly high in the large artery atherosclerosis group.

\section{CONFLICT OF INTEREST}

The authors declare that they have no competing interests in publishing this article.

\section{ACKNOWLEDGEMENTS}

Other colleagues of Neurology Department of BSMMU, residents of Neurology, staff of Cath Lab and Radiology and Imaging.

\section{REFERENCES}

Adams, H. P., Bendixen, B. H., Kappelle, L. J., Biller, J., Love, B. B., Gordon, D. L., \& Marsh, E. E. (1993). Classification of subtype of acute ischemic stroke. Definitions for use in a multicenter clinical trial. TOAST. Trial of Org 10172 in Acute Stroke Treatment. Stroke, 24 (1), 35 41. https://doi.org/10.1161/01.str.24.1.35

Adamson, J., Beswick, A., \& Ebrahim, S. (2004). Is stroke the most common cause of disability? JournalofStrokeandCerebrovascularDiseases, 13 (4), 171 - 177. https://doi.org/10.1016/j. jstrokecerebrovasdis.2004.06.003

Assad, S., Zafar, F., Tariq, W., Shoaib, R. F., Shah, A., Siddique, M., \& Zaki, A. (2018). Frequency of ischemic stroke subtypes based on toast classification at a tertiary care center in Pakistan. Asian Journal of Neurosurgery, 13 (4), 984. https://doi.org/10.4103/ajns. ajns_365_16 
Ay, H., Benner, T., Murat Arsava, E., Furie, K. L., Singhal, A. B., Jensen, M. B., Ayata, C., Towfighi, A., Smith, E. E., Chong, J. Y., Koroshetz, W. J., Sorensen, A. G. (2007). A computerized algorithm for etiologic classification of ischemic stroke. Stroke, 38 (11), 2979 - 2984. https://doi.org/10.1161/ strokeaha.107.490896

Barnett, H. J. (2000). Causes and severity of ischemic stroke in patients with internal carotid artery stenosis. JAMA, 283 (11), 1429. https://doi. org/10.1001/jama.283.11.1429

Beg, M. A., Ahmad, K., \& Renjen, P. N. (2015). Epidemiological study of incidence and risk factors of Ischemic stroke subtypes according to Trial of ORG 10172 in acute stroke treatment criteria: A 3 years, hospitalbased study. International Journal of Medicine and Public Health, 5 (1), 50. https:// doi.org/10.4103/2230-8598.151258

Bender, M., Jusufovic, E., Railic, V., Kelava, S., Tinjak, S., Dzevdetbegovic, D., Mot, D., Tresnjo, M., Lakicevic, S., Skobic, N. P., \& Sinanovic, O. (2017). High burden of stroke risk factors in developing country: The case study of Bosnia-Herzegovina. Materia Socio Medica, 29 (4), 277 - 279. https://doi.org/10.5455/ msm.2017.29.277-279

Bhowmik, N. B., Abbas, A., Saifuddin, M., Islam, M. R., Habib, R., Rahman, A., Haque, M.A., Hassan, Z., \& Wasay, M. (2016). Ischemic strokes: Observations from a hospital-based stroke registry in Bangladesh. Stroke Research and Treatment, 2016, 1 - 13. https://doi. org/10.1155/2016/5610797

Caso, V., Paciaroni, M., Agnelli, G., Corea, F., Ageno, W., Alberti, A., Lanari, A., Micheli, S., Bertolani, L., Venti, M., Palmerini, F., Billeci, A. M., Comi, G., Previdi, P., \& Silvestrelli, G. (2010). Gender differences in patients with acute ischemic stroke. Women's Health, 6 (1), 51 - 57. https:// doi.org/10.2217/whe.09.82

Cotter, P. E., Agarwal, S., \& Martin, P. J. (2011). Etiologic investigation of ischemic stroke in young adults. Neurology, 7 7(21), 1932 - 1933. https://doi.org/10.1212/ wnl.0b013e318239c0e8

De Silva, D. A., Woon, F.-P., Lee, M.-P., Chen, C. P. L. H., Chang, H. M., \& Wong, M. C. (2007). South Asian patients with ischemic stroke. Stroke, 38 (9), 2592 - 2594. https://doi.org/10.1161/ strokeaha.107.484584
Deb, P., Sharma, S., \& Hassan, K. M. (2010). Pathophysiologic mechanisms of acute ischemic stroke: An overview with emphasis on therapeutic significance beyond thrombolysis. Pathophysiology, 17 (3), 197 - 218. https://doi.org/10.1016/j. pathophys.2009.12.001

Donkor, E. S. (2018). Stroke in the 21st Century: A snapshot of the burden, epidemiology, and quality of life. Stroke Research and Treatment, 2018, 1 - 10. https://doi. org/10.1155/2018/3238165

Farhoudi, M., Pashapour, A., Alizadeh, M., Ladan, A., \& Mostafaei, S. (2019). Epidemiology and risk factors of stroke in Tabriz, Iran: A population based study. Journal of Experimental \& Clinical Neurosciences, 6 (1), 1 - 4. https://doi. org/10.13183/jecns.v6i1.93

Feigin, V. L., Forouzanfar, M. H., Krishnamurthi, R., Mensah, G. A., Connor, M., Bennett, D. A., \& Murray, C. (2014). Global and regional burden of stroke during 1990 - 2010: Findings from the Global Burden of Disease Study 2010. The Lancet, 383 (9913), 245 - 255. https://doi. org/10.1016/s0140-6736(13)61953-4

Flaherty, M. L., Kissela, B., Khoury, J. C., Alwell, K., Moomaw, C. J., Woo, D., Khatri, P., Ferioli, S., Adeoye, O., Broderick, J. P., \& Kleindorfer, D. (2013). Carotid artery stenosis as a cause of stroke. Neuroepidemiology, 40 (1), 36 - 41. https://doi.org/10.1159/000341410

Fure, B., Wyller, T. B., \& Thommessen, B. (2005). TOAST criteria applied in acute ischemic stroke. Acta Neurologica Scandinavica, 112 (4), 254 - 258. https://doi.org/10.1111/ j.1600-0404.2005.00470.x

Harris, S., Sungkar, S., Rasyid, A., Kurniawan, M., Mesiano, T., \& Hidayat, R. (2018). TOAST subtypes of ischemic stroke and its risk factors: A hospital-based study at Cipto Mangunkusumo Hospital, Indonesia. Stroke Research and Treatment, 2018, 1 - 6. https:// doi.org/10.1155/2018/9589831

Islam, M. N., Moniruzzaman, M., Khalil, M. I., Basri, R., Alam, M. K., Loo, K. W., \& Gan, S. H. (2012). Burden of stroke in Bangladesh. International Journal of Stroke, 8 (3), 211 - 213. https://doi. org/10.1111/j.1747-4949.2012.00885.x

Jacková, J. (2017). Risk factors in subtypes of ischemic stroke: Community based study in Brno, Czech Republic. https://doi. org/10.26226/morressier.58e389b0d462b8 0292384c98 
Kang, D. W., Chalela, J. A., Ezzeddine, M. A., \& Warach, S. (2003). Association of Ischemic Lesion Patterns on Early Diffusion-Weighted Imaging with TOAST Stroke Subtypes. Archives of Neurology, 60 (12), 1730. https:// doi.org/10.1001/archneur.60.12.1730

Kannan, R., Alex, A. G., \& Sudeep, K. (2017). A clinical study of factors predicting prognosis in acute ischemic stroke in a tertiary care center in north Kerala. International Journal of Research in Medical Sciences, 5 (10), 4344. https://doi.org/10.18203/2320-6012. ijrms20174555

Karn, R., \& Subedi, K. (2018). Study of the outcome differences among the ischemic stroke subtypes based on TOAST Classificationat Tribhuvan University Teaching Hospital, Nepal. Nepal Journal of Neuroscience, 15 (3), 39 - 48. https://doi.org/10.3126/njn. v15i3.23280

Katan, M., \& Luft, A. (2018). Global burden of stroke. Seminars in Neurology, 38 (2), 208 - 211. https://doi.org/10.1055/s-0038-1649503

Kaul, S., Alladi, S., Jabeen, S. A., Bandaru, V. C. S., Ankem, U., Mekala, S., \& Naik, G. S. (2018). Intracranial atherosclerosis is the most common stroke subtype: Ten-year data from Hyderabad stroke registry (India). Annals of Indian Academy of Neurology, 21 (3), 209. https://doi.org/10.4103/aian.aian_86_18

Kim, W. S., Bae, H. J., Lee, H. H., \& Shin, H. I. (2018). Status of rehabilitation after ischemic stroke: A Korean nationwide study. Annals of Rehabilitation Medicine, 42 (4), 528 - 535. https://doi.org/10.5535/arm.2018.42.4.528

Kolominsky-Rabas, P. L., Weber, M., Gefeller, O., Neundoerfer, B., \& Heuschmann, P. U. (2001). Epidemiology of ischemic stroke subtypes according to TOAST criteria. Stroke, 32 (12), 2735 - 2740. https://doi.org/10.1161/ hs1201.100209

Lee, J. D., Weng, H. H., Wu, C. Y., \& Wu, H. M. (2010). Stroke risk factors and subtypes in different age groups: A hospital-based study. Neurology India, 58 (6), 863. https://doi. org/10.4103/0028-3886.73747

Manosalva, H. A., \& Jeerakathil, T. (2016). Ethnic, racial, and geographic variations in stroke risk, and risk factors associated with stroke. In S. Seshadri \& S. Debette (Eds.), Risk factors for cerebrovascular disease and stroke (pp.311 - 326). Oxford University Press. https://doi. org/10.1093/med/9780199895847.003.0019
Palm, F., Urbanek, C., Wolf, J., Buggle, F., Kleemann, T., Hennerici, M. G., Inselmann, G., Hagar, M., Safer, A., Becher, H., \& Grau, A. J. (2012). Etiology, risk factors and sex differences in ischemic stroke in the Ludwigshafen stroke study: A population-based stroke registry. Cerebrovascular Diseases, 33 (1), 69 - 75. https://doi.org/10.1159/000333417

Pathak, A., Kumar, P., Pandit, A. K., Chakravarty, K., Misra, S., Yadav, A. K., \& Prasad, K. (2018). Is prevalence of hypertension increasing in first-ever stroke patients?: A hospital-based cross-sectional study. Ann Neurosci, 25 (4), $219-222$.

Rukn, S. A., Mazya, M. V., Hentati, F., Sassi, S. B., Nabli, F., Said, Z., Faouzi, B., Hashim, H., Abd-Allah, F., Mansouri, B., Kesraoui, S., Gebeily, S., Abdulrahman, H., Akhtar, N., Ahmed, N., Wahlgren, N., Aref, H., Almekhlafi, M., \& Moreira, T. (2019). Stroke in the Middle-East and North Africa: A 2-year prospective observational study of stroke characteristics in the region - Results from the Safe Implementation of Treatments in Stroke (SITS) - Middle-East and North African (MENA). International Journal of Stroke, 14 (7), 715 - 722. https://doi. org/10.1177/1747493019830331

Shakya, D., Shrestha, R., Dhungana, K., Kafle, R., \& Bhatta, S. (2019). Ischemic stroke: Observations and analysis of stroke patients admitted in a tertiary hospital of Kathmandu. Journal of Kathmandu Medical College, 8 (2), 66 - 71. https://doi.org/10.3126/jkmc. v8i2.28166

Taj, F., Zahid, R., Syeda, U. R., Murtaza, M., Ahmed, S., \& Kamal, A. K. (2010). Risk factors of stroke in Pakistan: A dedicated stroke clinic experience. Canadian Journal of Neurological Sciences / Journal Canadien Des Sciences Neurologiques, 37 (2), 252 - 257. https://doi. org/10.1017/s0317167100010015

Tan, Y. F., Zhan, L. X., Chen, X. H., Guo, J. J., Qin, C., $\&$ Xu, E. (2018). Risk factors, clinical features and prognosis for subtypes of ischemic stroke in a Chinese population. Current Medical Science, 38 (2), 296 - 303. https://doi. org/10.1007/s11596-018-1878-1

Tian, D. Y., \& Fan, D. S. (2018). Risk factors, regional disparity and trends of ischemic stroke etiologic subtypes. Chinese Medical Journal, 131 (2), 127 - 129. https://doi. org/10.4103/0366-6999.222332 